\title{
On the Development of Current Situation and Countermeasure of the New Media Art Professional Education
}

\author{
ShangDuan- $\mathrm{Wu}^{1}$ \\ ${ }^{1}$ City College, Wuhan University of Science and Technology, Wuhan Hubei 430083)
}

Keywords: The new media art professional education; Dilemmas; Countermeasures; expectation

\begin{abstract}
Along with the rapid development of science and technology, people's life style and life attitude has changed greatly. The traditional art methods cannot meet people's spiritual needs, visual image habits has also changed. The new media art is the product of the era, the rise of it has brought new changes to the current art education. Based on the forming background of the new media art professional education, this paper has analyzed on the present dilemma of the new media art professional education, furthermore, from the state, universities and all sectors of society, has puts forward some Suggestions to cope with the operability of several levels, from the nationalization, the internationalization and postmodern three dimensions has predicted its developing prospects.
\end{abstract}

\section{Introduction}

The appearance of the new media art professional education is not merited events, it has been established by the development of science and technology and the influence of international new media artists, new media art in China has grown vigorously. As the new things of high education, its development has highlighted the exuberant vitality, but has been not plain sailing, there is some problems to be solved in the process of its development.

\section{The forming background of the new media art professional education}

From the beginning of the end of the 20th century, " the new media art professional education" has frequently appeared in the domestic various types of media, at present, the term is already a household name just as famous brand. The establishment of the new media art professional education in China is only about 10 years, while the abroad has a history of nearly 20 years, compared with western countries, shorter history in China. It is also not accidental events in our country, it has been established by the development of science and technology and the rise of international and domestic new media art. Specifically, in our country, the forming background of the new media art professional education has the following several aspects:

The new media art professional education belongs to education category, at the same time, the education also belongs to an important part of social development. A variety of media, means, methods has been used in the education, which are closely linked to the humanities environment and the development of science and technology. Along with the popularity of personal computers, the individual life has been involved in the information revolution which Traits for a bit as the characteristics. The development of art education has been faced with great changes and challenges with the development of science and technology, for the artistic creation, the traditional palette in the present has largely been replaced the keyboard, mouse, the continuous upgrading of the hardware and software, also makes more and more space for the art creation. 
In the 1980 s, western new media artists such as nam June paik, bill viola, Tony Austin road, etc., their art activities media has been multimedia related technologies involved in video, audio, etc. The new media has also created new aesthetics, which is based on new media (including digital media such as computers, televisions, projectors, printers, print machine, stereo, etc.) and the creation of art , we are collectively known as the new media art. Represented by these new media artist western figures, they organize various exhibitions and exchanges, which ultimately has drived the birth and development of the entire western new media art in the $80 \mathrm{~s}$.

In the late $1980 \mathrm{~s}$, China has a few video artists begin to use this new media for artistic creation. But this does not belong to the mainstream of the art at the time, belongs to the edge of the art. In 1996, the exhibition of 《Phenomenon• image》successfully held in China, which showed that the general standard of China's new media art and its vitality, times. After the mid 1990s, with the improvement of the domestic PC penetration, more and more people are engaged in the creation of the new media art, many major cities across the country held photography, video, animation and other various types of new media art exhibition, at the same time, social also has a lot of demand for computer art creation talents, in the face of this particular time background, new media art education arises at the historic moment.

\section{The New Media Art Professional Education Present Dilemmas}

Along with the reform of the higher education running system and the rapid development of market economy, China's universities has increased the student enrollment of all kinds of design majors. But the current many universities teachers still maintain the original level, the new media art professional teachers, basically all are composition of teachers who have been on attention in recent years or are engaged in the new media art activity research and computer professional teachers, even so, universities are also short of teachers, teachers are specialityly engaged in the new media art activity research is a handful.

Due to the lack of new media art professional teachers, many of the new media art teaching without depth, the precision and the scope, the art design education without a clear character and tendency, just the free surface.Therefor, students are lack of confidence once entering the society, afraid of undertaking large engineering and design task, can't afford to break, which virtually has delayed the working position of the individual; And as time goes on, some problems maybe appear such as design thinking is not active, the lack of innovation ability, which caused by lack of knowledge reserves。

The term "new media art", belongs to the foreign concept, in our country till sprout too soon, relevant academic research began, so whether in the new media art practice, or on the curriculum system setting can only be "touch stone across the river" . In view of the new media art education relatively lagging situation, some universities actively take measures to organize the teachers to go abroad to learn, at the same time, innovation, reform boldly curriculum setting, teaching means, and has obtained the certain effect. However universities overemphasis on the operation of the software in digital media art teaching, for example, curriculum system sets up a large number of software practice courses. This kind of ignoring the artistic creation, stays excessively in the technical level of the teaching, make students original works often lack of originality. Visible, the development of new media art still Mired in a passive, students are busy in practicing a variety of software and have no time to consider the art language, design style, ignore the exploration of art design is the most essential things.

In addition, the construction of teaching material is a bottleneck which restricts the development of the new media art professional education. At present we haven't form a complete set of teaching 
materials to meet the needs of the new media art professional teaching. So, students are often no teaching materials, and are mostly in accordance with the case of teacher's teaching practice.

At present, the problem universally existing in the construction of the new media art professional education in universities is the infrastructure construction backward. For example, a comprehensive university, art students, more than 2000, but its teaching equipment is only more than 400 computers, other expensive price, fully functional device is almost zero. And according to students' feedback, even so limited computer, often use not conveniently, computers run slowly and often freezes.

Such cases, seriously restrict the development of new media art professional education. No advanced digital information technology equipment, lack funding will bring significant negative impacts about the new media art professional education.

The new media art belongs to a cross discipline, needs interdisciplinary professionals to be involved in the artistic creation. The separation phenomenon in current training mode is more prominent, the education system is not conducive to Cultivat inter-disciplinary talents, and will inevitably make talents not adapt to the demand of the society.

At present, because of the unreasonable structure of teachers and lacking of teaching facilities, students get skills through software operation, but without a good ascension practice ability and neglect art theory knowledge absorption, as a result, graduates lack of competitiveness. Current society often appear this kind of phenomenon, talents who understand digital technology and artist activity are shortage.

\section{The Countermeasures of the New Media Art Professional Education}

As the new thing in high education, the new media art professional education is flattered by the social from all walks of life from the date of birth. But we also have to face the reality, from the objective reality, if financial resources, teaching staff, teaching facilities and the external environment is not dominant, and rush blindly to open this professional, will not only bring bad effects on the healthy development of the school itself and the students' self development, but also a huge waste for education resources. In order to make the new media art carry out in the domestic, the social from all walks of life should be multi-pronged, cooperate with each other, give corresponding support、supervision , and know fully and correctly. Therefore, from the following several aspects:

Approved by the national education departments to unify, from teachers, the curriculum setting, the teaching material selection, the classroom configuration, the hardware construction and the external environment such as a comprehensive ability of running a few surface. In addition, the ministry of education can regularly cycle in some universities to carry out the teachers' professional training, a nationwide selection of high-level experts to give lectures, cultivate new media art professional teachers to create a good atmosphere. For those who don't have running qualification of universities should determined to stop or cancel the opening of the professional.

The local university should focus on its own reality, mine area characteristic culture for the development of personalized art education. If you don't have school condition, don't rush to open this major. The following some basic work can be done

On the one hand, strengthen the communion between disciplines. local comprehensive universities open the new media art major, should according to their own discipline characteristic, foster strengths and circumvent weaknesses, play advantage, and consider integrating resources related disciplines, enable students to master "media convergence" design thinking and creative ability, to develop their own characteristics in the new media art talent training. In addition, we 
should strengthen international communication and cooperation of running and discussed in this field.

On the other hand, strengthen the construction and training of complex teachers. First of all, universities should establish a good incentive mechanism, in order to arouse the enthusiasm of teachers, to speed up the learning and mastering the advanced new media technologies. At present, the development of information technology with each passing day, the development of new media art is closely related with its development, not to advance is to go back, can't keep up with the progress of technology, will be eliminated. Second, to carry out international exchanges and cooperation is a quick way, selection of study more outstanding students and young teachers to the new media art education studying in more developed countries. Again, hire experts to give lectures, from the new media art teaching advantage prominent universities or socially prominent is engaged in the new media art education or invite relevant experts to give lectures in creative agency, in the cultivation of the students and teachers.

Third, universities should intensify efforts to organize the teacher according to personal expertise and experience in teaching to write teaching requirements and adapt to the new media technology development, reached the international leading level of the teaching material. Practice has proved that it is not easy under the current situation. The author suggested that we organize some good teachers to translate foreign languages or compile systematically advanced foreign universities teaching materials, this can yet be regarded as a good way to solve the domestic textbooks.

The new media art major is often referred as "noble major ". Therefore, in terms of most households, choose this major will bring parents and students huge economic pressure, the major learning will bring trouble to the student, at the same time, it may trigger a series of psychological and social problems.

\section{The Expectation of the New Media Art Professional Education}

Along with the rapid development of electronic technology, multimedia technology, the development of digital image art also changes with each passing day, has become a kind of basic language and tool , which has been widely penetrated into all kinds of art and design, such as in the field of film and television animation, a new image era. Thus, in the face of China's contemporary art education, is not only the issue of scale expansion, but just days before the arrival of the information revolution, discipline adjustment, integration of talent, in the traditional art and new media art atmosphere of symbiosis, actively face the opportunities and challenges brought by the information revolution. Can predict the development of new media art professional education will tend to be in the following aspects:

Return to nationalization. In the context of modern art, nationalization in new media art creation activity is often obscured. "Sixth generation" of new image motion film opened China's national culture which is mixed in the context of modern, China life situation was unprecedented in the "new media" dismembered, it with the present daily life narration and sensations gained by the people here. The vitality of the "state" due to its use of the "head-up", participation and intervention method, makes the man behind the camera to the fate of the predecessors and the camera is the same, they were in a plane. Taken into a process of intervention, a total of "emotion" is generated. [1] For new media art education lit the dawn__raining the author's ethical, let the vitality in virtually disappear in the text.

Towards the internationalization. The present fashionable words are "the more national is the more the world." Internationalization is here rests in nationality, therefore did not contradict with nationalization. The new media art professional education is a process of internationalization, people 
on the receiving new things, at the same time, can't completely abandon the old things,but find a balance point, let them co-prosperity coexistence.

Across the postmodern. All of the art in the context of postmodern culture will be played on the imprint of the post-modernism, all the rules in the postmodern has dispeled, everything can be a criterion, the new things as well as the new media art has not been spared from the magic of the postmodern. Therefore, we need practice to construct the new media art and the new media professional education, beyond the postmodern hurricane.

The new media art professional education starts late in our country, different from the objective reality of developed countries, accordingly, we want to find a suitable for China's new media art professional education pattern, just like "touch stone across the river", to explore the process will be subjected to various setbacks, hardships and clinking. However, believe that as long as we work together, to build beautiful spiritual home and the dreamof "poetic dwelling"[2]

\section{References:}

[1] Zhu Zhi-gang: The new media art major education and research, "journal of nanjing college of art, 2009, 4, 36 pages.

[2] Liu Zi-li: The new media brings the aesthetic thinking, "philosophy", 2010, 5, page 45. 